\title{
Applying a Darwinian model to the dynamic capabilities view: Insights and issues ${ }^{1}$
}

\author{
Peter Galvin, ${ }^{*}$ John Rice, ${ }^{\dagger}$ and Tung-Shan Liao ${ }^{\ddagger}$
}

\begin{abstract}
The Darwinian logic of evolution occurring via the mechanisms of variation, selection and retention provides a possible theoretical framework from which to further develop the dynamic capabilities view. Presently, criticized for lacking a theoretical foundation and featuring a degree of confusion concerning how it aligns with the resource-based view, the dynamic capabilities view would benefit from greater clarity concerning its assumptions, theoretical base and the development of a series of testable predictions. We test elements of a potential Darwinian style framework through variation-focused hypotheses using panel data for 190 Australian service firms. Our results highlight the importance of market development as a basis for variation, however, the impact of dynamic capabilities upon a likely antecedent of selection was not clear and highlighted a nuanced relationship between capability development, market development and sales growth in an small-and-medium-sized enterprise environment. We conclude that applying a Darwinian lens to the dynamic capabilities view is challenging without longer time series data and additional measures, but such an approach remains theoretically attractive and further investigation may help clarify how we conceptualize the relationship between the dynamic capabilities view and resourcebased view.
\end{abstract}

Keywords: dynamic capabilities, resource-based view, evolutionary theory, Darwinian models, firm performance

$\mathrm{T}$ he resource-based view (RBV) provides a theoretical framework that explains how resources may provide a basis for competitive advantage (Barney, 1991; Peteraf, 1993). Emphasizing imperfections in factor markets as a source of rents, the RBV has been criticized on the basis of its static equilibrium logic (Priem \& Butler, 2001). In comparison, the dynamic-capabilities view (DCV) has been heralded as potentially overcoming some of the potential weaknesses of the RBV. Positioned as a dynamic model highlighting path-dependent processes that allow firms to adapt to changing environments by building, integrating and reconfiguring a firm's resource base (Teece, Pisano, \& Shuen, 1997), the DCV builds on evolutionary theory as opposed to the neoclassical economic theory of the RBV.

The promise of the DCV has slowly given way to a range of practical issues from a lack of clarity around the core concepts and a related problem of a lack of - or at least unclear - theoretical foundations (Ambrosini \& Bowman, 2009; Arend \& Bromiley, 2009). Peteraf, Stefano, and Verona (2013)

1 This paper was accepted in 2012 under the Editorship of Charmine Hartel.

* Curtin Graduate School of Business, Curtin University, Perth, Western Australia, Australia

$\dagger$ Griffith Business School, Griffith University, Gold Coast, Queensland, Australia

$\ddagger$ College of Management, Yuan Ze University, Chungli, Taoyuan, Taiwan

Corresponding author: Peter.Galvin@gsb.curtin.edu.au 
suggest that two distinct 'clubs' have emerged within the field centred around the two seminal papers in the field - Teece, Pisano, and Shuen (1997) and Eisenhardt and Martin (2000). The Teece 'club' (e.g., Teece \& Pisano, 1994; Teece, Pisano, \& Shuen, 1997; Winter, 2003) presents the DCV in evolutionary terms with a distinct Schumpterian flavour. In comparison, Eisenhardt and Martin (2000) see dynamic capabilities as a response to volatile environments where dynamic capabilities exist as best practices and heuristics. While the Teece perspective suggests that dynamic capabilities may be a source of competitive advantage, the Eisenhardt and Martin (2000) position is clear that dynamic capabilities can be a source of temporary competitive advantage only. It is on this basis that this perspective sees a greater need to draw upon RBV to understand a firm's competitive position over time.

It is these alternative theoretical underpinnings that lead to the highly ambiguous relationship between the RBV and the DCV within the broader literature. While some authors see the DCV as independent of RBV, other authors have presented the DCV as simply an extension of the RBV or even as part of it - "We... include all organizational capabilities, "dynamic" or otherwise, in a dynamic resource-based view' (Helfat \& Peteraf, 2003: 997). However, integrating the RBV and DCV perspectives is difficult as the DCV is a disequilibrium approach that focuses on environmental fit rather than competitive advantage specifically and addresses resource building - as opposed to the resource picking of RBV (Makadok, 2001). Until there is clarity around whether the DCV should be moving to integrate with the RBV (along the lines of Makadok, 2001; Helfat \& Peteraf, 2003; Helfat, Finkelstein, Michael, Peteraf, Teece, \& Winter, 2007; Newey, Verreynne, \& Griffiths, 2012), or whether the DCV should be conceptualized as an independent, but complementary, theory to the RBV that draws explicitly upon evolutionary economics, it will be exceedingly difficult to build the necessary theoretical foundations necessary to advance the DCV.

Our arguments in this paper clearly align with the 'independent' orientation on the basis that the underlying assumptions and principle arguments of the two views are divergent. However, we also see the RBV and the DCV as complementary as the RBV presents a logic as to how resources may sustain competitive advantage via imperfect markets, whereas the DCV provides a basis for understanding how these resources are built and evolve over time. To explain the need for the DCV's independence we begin by detailing each theory's theoretical roots. We then build on the evolutionary heritage to suggest that the Darwinian logic of variation, selection and retention may provide a clear process for understanding the process by which firms develop over time in concert with changing environmental conditions. An evolutionary model builds upon the relatively underutilized tradition of evolutionary approaches in strategy (Barnett \& Burgelman, 1996; Stoelhorst, 2008) and aligns well with the inherent nature of strategy with its bounded rationality (at best), issues of learning and iterative feedback loops. A Darwinian interpretation of the DCV also provides a specific theoretical foundation for developing hypotheses concerning the different stages of this evolutionary model that were then tested via panel data.

\section{LITERATURE REVIEW}

Neoclassical economic models whose features include homogeneous markets (and thus products), rational actors, mobile resources, lack of transaction costs and perfect information allow for an understanding of the theoretical conditions where economic profits will be non-existent. In such situations, superior performance can be best explained considering the conditions under which the different neoclassical assumptions are violated. It is on the basis of such market imperfections that the RBV perspective has been built with resource heterogeneity providing the cornerstone for explaining superior performance (Barney, 1991; Peteraf, 1993; Peteraf \& Barney, 2003). Rents may then accrue owing to these heterogeneous resources' value and rarity, and they may be sustained over time if these resources are not imitable or substitutable. 
However, exactly how organizations create or acquire these rare and valuable resources is not addressed other than to highlight how ex ante limits to competition on the basis of information asymmetries or luck may allow firms to acquire superior rent-generating resources (Barney, 1986; Peteraf, 1993). While the RBV has attracted criticism on a number of points (e.g., Porter, 1991; Williamson, 1999; Priem \& Butler, 2001), one key shortcoming is its inability to account for the creation and development of relevant resources and capabilities internally, and how firms may adapt these resource endowments to meet changing environmental and market conditions (Teece, Pisano, \& Shuen, 1997).

With these short-comings in mind, the seminal paper by Teece, Pisano, and Shuen (1997) introduced dynamic capabilities as a potentially evolutionary approach to explain the development and reconfiguration of resources within firms. The DCV highlights the potential for path-dependent organizational processes that allow for firms to adapt to (rapidly) changing competitive conditions. Their approach to dynamic capabilities is thus complementary, but independent to RBV (Winter, 2003). That is, RBV suggests how firms may create sustainable competitive advantage on the basis of particular resources, whereas the DCV helps to explain the dynamics within the firm that allow resources to develop over time and how these may be integrated, deployed and reconfigured to meet changing environments.

While this need for a dynamic resource-based theory was obvious for some (e.g., Barney, 2001; Helfat \& Peteraf, 2003; Winter, 2003), the relationship between the DCV and RBV is ambiguous. A significant portion of the most commonly cited papers in the field position dynamic capabilities as a complementing view to the RBV (e.g., Teece, Pisano, \& Shuen, 1997; Zollo \& Winter, 2002; Winter, 2003; Agarwal \& Selen, 2013). However, another 'club' of dynamic capabilities research (Schreyögg \& Kliesch-Eberl, 2007) approached the DCV as being far more aligned with RBV. Some (e.g., Eisenhardt \& Martin, 2000; Zott, 2003) have drawn a link between dynamic capabilities and performance - even if it is rarely conceptualized as being direct with the relationship being mediated by the firm's resources. It has also been suggested that the RBV and the DCV would do best to be integrated (Helfat, 2000; Makadok, 2001; Zott, 2003). Some are already working towards a level of integration such as Helfat and Peteraf (2003) who argue that all capabilities (including dynamic capabilities) are captured in a dynamic RBV. In a review paper, Ambrosini and Bowman (2009: 29) suggest that the DCV 'is argued to be an extension of the RBV; [and] it shares similar assumptions' (Barney, 2001b). Finally, the highest level of integration is seen in Helfat et al. (2007: 14) who propose that dynamic capabilities need to be valuable, rare, imperfectly imitable and nonsubstitutable as per Barney (1991) and that the 'types of isolating mechanisms that Rumelt (1984) lists apply to dynamic capabilities just as they do to other types of resources or capabilities'. It is therefore not surprising that Barney and Clark (2007: 249) criticize the DCV on the basis that it is not a dynamic model but is instead based upon RBV logic.

Part of this confusion stems from the lack of a clear theoretical foundation. The field features a mixing of assumptions and inconsistent theory application such as discussing the creation of rents through market imperfections alongside evolutionary paths based upon organizational routines (Arend \& Bromiley, 2009). Where authors have tried to provide a clear theoretical foundation (such as Helfat et al., 2007) they have tended to rely upon aspects of theory developed within the RBV. This reinforces the DCV's fractured nature and opens itself to the principal criticisms levelled against the RBV (e.g., being tautological).

We suggest that rather than trying to more closely integrate with the RBV, the DCV needs to highlight its differences to the RBV both in respect of its assumptions and its theoretical logic - thus positioning itself as independent from RBV theory. To do this, the DCV needs to clearly position itself as an evolutionary theory that builds upon the work of both evolutionary economists (e.g., Penrose, 1959; Nelson \& Winter, 1982; Schumpeter, 1982; Stoelhorst, 2005) and evolutionary management theorists (e.g., Barnett \& Burgelman, 1996; Aldrich \& Ruef, 2006; Durand, 2006; 
Mathews, 2006). One way to do this would be to clearly introduce biological concepts as part of a Darwinian model as a starting point for consistent theory building. This would then alleviate the expectation that the DCV can specifically address the drivers of competitive advantage. Rather, in a Darwinian model, the focus is upon evolutionary processes and superior performance is not an overt outcome as much as it is likely to be highly correlated with survival and strong growth. Thus, the focus remains upon the evolution of the firm and how resources are developed and deployed over time - thereby allowing traditional RBV to provide the theoretical logic as to how these resources may provide the basis for competitive advantage.

\section{HYPOTHESIS DEVELOPMENT}

The use of biological concepts in business-related evolutionary theory is not uncommon (e.g., Nelson \& Winter, 1982; Barnett \& Burgelman, 1996; Hodgson, 2004; Aldrich \& Ruef, 2006; Durand, 2006) though many authors have purposefully stayed away from utilizing the generalized Darwinian approach of variation, selection and retention on the basis of its questionable usefulness in the social sciences and the transferability of definitions and concepts (Hodgson, 2004, 2009). Others have found use for these concepts and consider them to be appropriate in given scenarios (Campbell, 1969; Aldrich, 1979; Aldrich, Hodgson, Hull, Knudsen, Mokyr, \& Vanberg, 2008). Such an approach immediately differentiates the DCV from the RBV. For instance, the dependent variable for the DCV is no longer performance, but rather survival and evolution of the firm within a disequilibrium model - as opposed to the economic equilibrium derived RBV (Stoelhorst, 2008).

A key issue in viewing the DCV via a Darwinian lens is determining how to identify the mechanisms of variation, selection and retention in a way that can be empirically tested. Appropriate empirical testing is important as Pablo, Reay, Dewald, and Casebeer (2007: 690) understates a key criticism of the field when they comment that 'empirical studies of dynamic capabilities remain relatively rare'. Before moving to the specifics of how these mechanisms can be specified and tested, it is necessary to address each mechanism in turn at a theoretical level.

Variation provides for heterogeneity across the industry. Dynamic capabilities - whether they emerge through the process of learning (Zollo \& Winter, 2002) or via managerial or entrepreneurial capacity (Zahra, Sapienza, \& Davidsson, 2006) allows firms to reconfigure their resources and capabilities to create heterogeneous positions within product markets. Even if firms start with the same resource endowments, the way that new resources and capabilities are developed, along with the way existing and new resources are integrated and deployed in different ways ensures heterogeneity. Variation will be pursued to achieve environmental fit. However, variation is not purely a response to changing environments as Pitelis and Teece (2009) highlight the potential for co-evolution where managers are able to shape markets (as well as markets impacting upon what actions firms undertake). In an evolutionary sense, this aligns neatly with Odling-Smee, Laland, and Feldman's (2003) notion of niche construction whereby firms contribute to the construction and destruction of their own and other niches. Thus, dynamic capabilities are critical in driving variation as they underpin a firm being able 'meet changing customer needs, and to sustain and amplify evolutionary fitness' (Teece, 2007: 1344).

Selection is most overtly visible via market-based competition - though it should be emphasized that this does not lead to or equate to optimization (Sober, 1984). The variation mechanism provides heterogeneity in product markets such that those firms that best fit with the environment will survive and grow, and, at the most basic level and in line with the Darwinian principle of natural selection, inappropriate variations will either need to adapt or become extinct over time. However, such a deterministic approach is unlikely to dominate the social sciences for a number of reasons including the institutional environment and the potential for niche construction as the dominant evolutionary mechanism rather than natural selection (Hodgson, 2004). Nevertheless, in the context 
of competitive markets and in the case of numerous small-and-medium-sized enterprises (SMEs) operating in these markets, the selection process may be more akin to the biological concept than elsewhere in the social sciences. Therefore, it is possible that traditional measures of performance such as profit are an antecedent of the selection process and in themselves provide a stimulus for future retention and variation by creating the cash resources to reinvest in a firm's routines and dynamic capabilities (and thus providing opportunities for further appropriate heterogeneity in time). In comparison, firms that perform poorly in respect of the selection mechanism will subsequently be challenged in future retention and variation-related activities owing to reduced opportunities to make investments in their resources and capabilities. While selection will be observed via product market competition, the selection mechanism highlights which resources and capabilities are creating value versus those that are not - leading to the notion of retention.

On the basis of this feedback from the market, retention sees firms institutionalize how they interact with the environment through embedding appropriate routines in their suite of activities and building new ones where appropriate - thereby building evolutionary pathways. The presence of dynamic capabilities allows for these resources and capabilities to be reconfigured such that the variation process may continue - thus beginning the cycle again. Hence, from an evolutionary perspective, dynamic capabilities allow for the variation across an industry. Feedback on the basis of environmental fit is provided by the selection mechanism, which then determines that which is retained and what needs to be built anew. Changes in the resource base through the application of dynamic capabilities then begin the process again.

\section{Variation and selection mechanisms}

From an evolutionary perspective, the variation mechanism leads to a range of alternative offerings to the market and the selection mechanism then sees some firms prosper, some simply survive and others eventually fail. How much variation is required is determined by the needs of the market, however, we suggest that in the case of small firms in highly competitive markets that almost continual variation in some manner will be required to be competitive. Such firms are unlikely to have very valuable resources that set it apart from other SME competitors (such as an exceptional brand, patents or an incomparable culture). Instead, they are more likely to compete via continual improvements in both their internal operations and their product offerings.

In considering the way that selection takes place on the basis of the variation we witness in the market, we use the term 'market development' in our model. Firms may continually adapt their market presence through a combination of new product and service releases (substantive and tangible changes in the market offerings of firms) and changes in advertising, distribution and market locations served (perceptual and positional market changes). Taken together, these represent a transformation of the competitive basis of the focal firm in its market (Srivastava, Fahey, \& Christensen, 2001; Agarwal \& Bayus, 2002). However, in addition, evolutionary theory views the environment as continually changing and firms may play a role in this co-evolutionary process to the extent that they may 'even create market change' themselves (Eisenhardt \& Martin, 2000: 1107). As firms may transform their market offerings as well as potentially transforming the market itself, we discuss the variation mechanism in respect of a firm's market development.

Assessing selection that occurs on the basis of variation is challenging in an empiric sense. We could look at firm survival (Hannan \& Freeman, 1984), however, firms with poor environmental fit may take years to be eliminated from an industry. We therefore consider not survival, but firm performance as the overt result of the selection mechanism. We therefore hypothesize:

Hypothesis 1: Firms that pursue high levels of variation through market development will have high levels of performance (as a reflection of the selection process). 


\section{Dynamic capabilities and the selection mechanism}

Our second hypothesis considers the role that dynamic capabilities play in driving variation (market development) and subsequent selection (performance). While variation is required to achieve environmental fit, any variation is actually possible because of changes that occur within the firm in respect of resources and capabilities - and it is these changes that may be driven by the presence of dynamic capabilities. Zollo and Winter (2002: 340) position learning as a source of dynamic capabilities and define them as 'a learned and stable pattern of collective activity through which the organization systemically generates and modifies its operating routines in pursuit of improved effectiveness'. It is the changes and modification of the routines component of this definition that are important in the empirical component of this paper.

Dynamic capabilities are a higher order capability (Eisenhardt \& Martin, 2000; Winter, 2003; Zahra, Sapienza, \& Davidsson, 2006) where both their development and deployment are underpinned by the learning process. Cyert and March's (1963) view of firm processes as 'learnt mechanisms' that enable firms to generate and adapt the behaviour of their operational routines in response to contextual changes highlights how learning is instrumental in determining a firm's capacity to create innovative responses to emergent contextual problems. However, not only does learning provide an impetus for the variation that we observe as market development, the organizational learning process also relies upon the accumulation of experience and knowledge that it garners from its existing processes (Cohen \& Levinthal, 1990; Cohen et al., 1996; Van Den Bosch, Volberda, \& De Boer, 1999). That is, learning provides a basis for variation and feedback on the success of such variation provides the basis for further learning - thus beginning the cycle anew. However, for this hypothesis we focus on how learning-enabled dynamic capabilities affect the variation and selection mechanisms and we therefore posit:

Hypothesis 2: Firms with developed dynamic capabilities in combination with more market development capabilities (variation) will experience higher levels of performance (as a reflection of the selection process).

\section{METHODS}

\section{Data and sample}

\section{The Business Longitudinal Survey}

We use longitudinal data drawn from the Business Longitudinal Survey provided by the Australian Bureau of Statistics (ABS) as a confidentialized unit record file. The Business Longitudinal Survey provides primary statistical information concerning growth and performance characteristics of Australian industrial firms. It provides 4-year panel data (1994-1995 to 1997-1998, coinciding with Australian financial years ending 30 June). It provides firm-level microdata on company finances (revenues, expenditures, debts and assets), profiles on employment, training and education, and information on the use of management practices at the firm level. The panel data supplied by the ABS is restricted to Australian SMEs with less than 200 employees.

\section{The sample}

The sample size of the entire Business Longitudinal Survey confidentialized unit record file exceeds 9,700 firms. We limit our investigation to non-manufacturing firms (excluding around 2,400 in total), as certain relevant questions were asked only of the non-manufacturing group. We removed firms from the sample that were not represented in all 4 years of data gathering. While we acknowledge that this created an inherent survivorship bias in our sample, we felt that such a screen 
was necessary to contain issues associated with new start-ups and struggling firm whose capability development and marketing arrangements may have coloured our analysis.

We also chose to look only at firms with 11 or more employees. This excluded many microorganizations and sole traders that would not, by definition, have sufficient procedural resources to undertake some of the activities of interest in this analysis. This left us with a subsample of 190 Australian firms in the services sector.

\section{Measures}

Our study employs three key measures - one assessing the breadth of capability development, one assessing market development activities and a dependent variable assessing sales growth. We utilized a principal component analysis arrangement in SPSS to establish underlying measures for the two focal issues of our study, namely capability development and market development.

\section{Capability Development}

For this study, we developed a measure that we called Capability Development via four variables, including a major change (upwards or downwards) in the use of the following processes:

- On-the-job training

- Management training

- Administrative computer systems

- Accounting software use

This factorial measure integrates key elements of dynamic capability development associated with increasing employee and managerial skills and developing information systems capabilities.

We rescaled the initial survey values to better reflect a logical semantic ordering, allocating 1 for firms reducing the use of such arrangements, 2 for firms reporting no change and 3 for firms increasing the use of such arrangements between years 1996 and 1997.

\section{Market Development}

Our measure of Market Development picks up three key activities, namely:

- Advertising

- Distribution

- Targeting of domestic markets

In similar vein to the measures underlying the Capability Development factor, we rescaled such that a major decrease in the use of such arrangements was rescored 1, no noted change was scored 2 and a major increase was scored 3.

\section{Firm performance}

To measure firm performance, we focused on sales growth between 1997 and 1998. While it was possible to use some form of profitability measure (e.g., return on assets) we chose sales growth as the firms were relatively established. Furthermore, profit variance can be influenced by factors associated with capital and innovation investments in the short term, while sales tends to be a more stable measure for most firms (Miller, Le Breton-Miller, \& Scholnick, 2008).

We chose to utilize the longitudinal aspect of the survey to measure sales growth in the year following the major changes discussed above. This allowed for a certain lag in the changes to the two focal activities (Capability and Market Development) and their concomitant impact on firm performance. 


\section{METHODS AND RESULTS}

Table 1 provides the factor loadings for our seven underlying items for our two focal measures of Capability Development and Market Development. The first component assesses the change in the use of activities that we see as important proxies for Capability Development, both in relation to employee training and in terms of IT development. The factor loadings and Cronbach's $\alpha$ for this measure are reported below. Likewise, the factor loadings in relation to the assessment Market Development, and the respective Cronbach's $\alpha$ for this measure, are provided.

The proposed relationships between our two capability measures and our firm performance measure is complex, so we decided to undertake two analyses to better assess the covariance of these factors in combination. We first assessed the mediating effect of Market Development on the relationship between Capability Development and Sales Growth (Figure 1).

The direct effect of Capability Development is shown to be non-significant $(p>.10)$. Likewise, the total effect of Capability Development on Sales Growth is determined by adding the direct and indirect effects, which sums as $-0.0435(p>.10)$. We can thus discern that, in our data set, Capability Development's total, direct and indirect effects on Sales Growth are non-significant at $p<.05$ (Zhao, Lynch, \& Chen, 2010). The overall model fit for the mediated model was strong $\left(R^{2}\right.$ of 0.2340 , $p<.0001)$, although this is primarily driven by the very strong covariance of the Market Development factor and the Sales Growth dependent variable.

The mediated model presented some findings that were not in line with the anticipated effects hypothesized earlier. In support of Hypothesis 1, we did find clear and strong support for the notion that firms that undertook market development activities saw growth in sales.

\section{TABle 1. Rotated COMPONent MATRIX}

\begin{tabular}{lcc}
\hline \hline & \multicolumn{2}{c}{ Component } \\
\cline { 2 - 3 } & $1(\alpha=0.71)$ & $2(\alpha=0.75)$ \\
\hline Major change - 1996-1997 - advertising & 0.018 & 0.722 \\
Major change - 1996-1997 - distribution & 0.091 & 0.780 \\
Major change - 1996-1997 - markets targeted - domestic & 0.210 & 0.719 \\
Major change - 1996-1997 - on-the-job training & 0.717 & 0.138 \\
Major change - 1996-1997 - management training & 0.717 & 0.103 \\
Major change - 1996-1997 - other admin computer systems & 0.736 & 0.083 \\
Major change - 1996-1997 - accounting software & 0.716 & 0.062 \\
\hline \hline
\end{tabular}

Note. Extraction method: principal component analysis; rotation method: Varimax with Kaiser normalization.

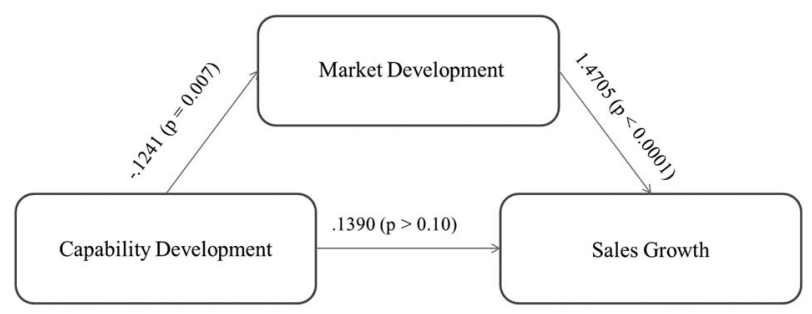

Figure 1. Mediated model of capability development, market development and sales growth 


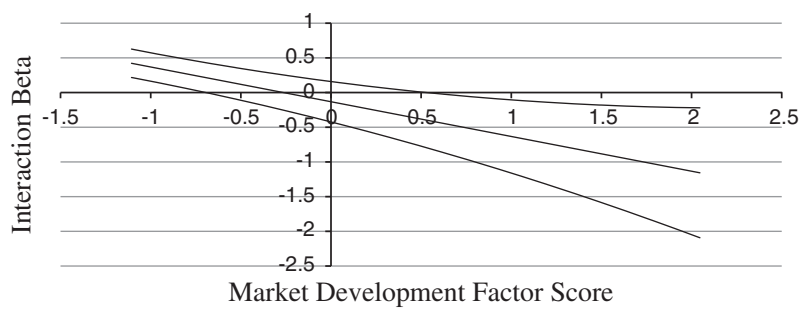

Figure 2. Moderation efFect PROBE fOR CAPABiLity AND MARKET DEVELOPMENT AT LEVELS OF MARKET DEVELOPMENT

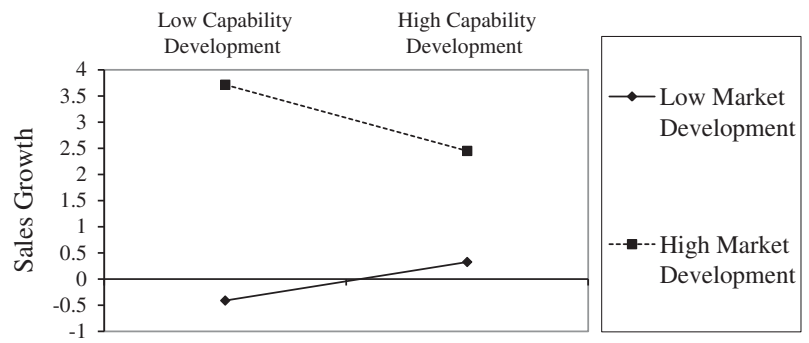

Figure 3. Moderation effects for CAPABiLity AND MARKET DEVELOPMENT AT LeVELS Of CAPABILITY DEVELOPMENT

However, the effect between Capability Development and Market Development was the opposite of what was hypothesized. Indeed, we observed a significant and negative covariance between capability development activities and market development activities within our sample.

Furthermore, the unmediated relationship between Capability Development and Sales Growth was found to be statistically non-evident in our sample.

We chose to explore more deeply the interrelationship between Capability Development and Market Development, which is a focus of Hypothesis 2, by exploring the moderating effect of Market Development on Capability Development in anticipating Sales Growth.

The results for the moderated analysis are presented in the following tables and figures. The constant in the following equation shows that sales grew by $1.5202 \%$ as a baseline. Consistent with the directionality and significance shown in the mediated model earlier, the development of capabilities actually covaried negatively with Sales Growth. This may reflect a longer lag than is evident in our model, or a crowding out of market-related capability development by spending on training and IT systems development. In some ways, this is potentially consistent with an evolutionary perspective as a lack of sales growth may stimulate a desire to invest in capability development.

Consistent with the mediated model presented earlier, Market Development has a strong, positive and significant effect on Sales Growth. Every standard deviation increase along the Market Development factor increases sales by around $1.5622 \%$.

The interaction effect of Capability Development and Market Development is also significant, although the $\beta$ coefficient is negative. This indicates that as Market Development activities increase, the size of the interaction effect between our two independent variables declines.

To better assess this phenomenon, we present Figures 2 and 3. Figure 2 shows that at low levels of Market Development, there is a significant and positive interaction effect between Capability Development and Market Development. In essence, this supports the notion that firms may operate in a phase of capability build-up, where low investment in market development is partially compensated by investments in training and IT development. This is shown in Figure 2, where the LLCI $(p=.05)$ crosses the zero horizontal axis at negative 0.7869 standard deviations of the Market Development factor. 
Generally, however, investments in capabilities seem to come at the expense of performance for most firms if they occur as an alternative to market development activities. The ULCI crosses the zero horizontal axis at positive 0.5928 standard deviations of the Market Development factor. This suggests that at levels above around 0.6 standard deviations of Market Development activities, the product of Capability Development and Market Development becomes negative and significant - suggesting a deteriorating return on investment above this level where market development activities are sacrificed to fund capability development activities.

Figure 3 presents these effects more intuitively. A firm with low Capability Development will see a significant and positive increase in sales as it invests in Market Development activities. However, a firm investing heavily in both Capability Development and Market Development will tend to see lower Sales Growth.

\section{DISCUSSION AND CONCLUSIONS}

The purpose of this paper was to consider dynamic capabilities through an evolutionary lens using the Darwinian logic of variation, selection and retention. By adopting such an approach, we set out to consider how firms evolve in competitive markets and how this evolution positions them for the longer term selection that occurs over time. This approach allows the DCV logic to be conceptualized as independent (but complementary) to the RBV in that it explains how firm resources and capabilities evolve as opposed to which resources and capabilities drive superior performance.

Hypothesis 1 highlighted the importance of variation in respect of subsequent selection as measured by sales growth. In a Darwinian model, variation does not have to be high to result in selection and thus survival. Rather it is the appropriateness of the variation that is important. Extreme variants may well fail unless there is a clear environmental reason for their existence. And yet our model showed that high levels of variation were associated with high levels of performance (i.e., a likely antecedent of selection). This has implications for the application of the DCV as initial discussion of dynamic capabilities focused upon their relevance in rapidly evolving markets where rapid internal changes would be required to cope with future environmental uncertainty and quickly evolving competitors (Teece, Pisano, \& Shuen, 1997).

SME service firms are unlikely to universally face such a dynamic environment. Instead, we suggest an alternative logic for this suggested need to continually adapt to achieve high levels of performance. Most small service firms are unlikely to contain any significant resources that are valuable, rare, inimitable and non-substitutable (Barney, 1991). Rather, these firms are most likely to compete on the basis of how they develop, redevelop and integrate particular resources related to market development. Those firms that do not continually adapt their market offering on the basis of changes in their routines are likely to be very quickly left behind.

The strong and positive results in relation to Hypothesis 1 provides support for the notion that Market Development activities increase sale growth. This is shown both in the mediated model presented in Figure 1, and also in the regression analysis presented in Table 2. Variation provides for heterogeneity across industries and the creation of heterogeneous positions within product markets through engaging in various market development activities has a clear impact upon sales growth - and in time one would therefore expect in respect of the selection mechanism.

Our findings in relation to Hypothesis 2 are far more nuanced. The initially unexpected negative directionality of the $\beta$ coefficient reported in Figure 1 was explored further by conducting an investigation of the moderating effects of Market Development on the relationship between Capability Development and Sales Growth. Here, we find strong evidence of the need to carefully balance Capability Development and Market Development activities, along with strong evidence of the primacy of Market Development activities within the models presented above in determining Sales Growth. 
TABLE 2. REgRESSION RESULTS - DEPENDENT VARIABLE $=$ SALES GROWTH

\begin{tabular}{lccrr}
\hline \hline & $\beta$ & $S E$ & $t$ & \multicolumn{1}{c}{$p$} \\
\hline Intercept & 1.5202 & 0.0860 & 17.6846 & $<.0001$ \\
$\begin{array}{l}\text { Direct effects } \\
\quad \text { Capability Development (CD) }\end{array}$ & -0.1320 & 0.1345 & -0.9817 & .3275 \\
$\quad$ Market Development (MD) & 1.5622 & 0.1937 & 8.0668 & $<.0001$ \\
$\begin{array}{l}\text { Interaction } \\
\quad \text { CD by MD }\end{array}$ & -0.501 & 0.1713 & -2.9221 & .0039 \\
\hline \hline
\end{tabular}

Note. Overall regression model results $\left(R^{2}=0.2676, F=22.6553, p<.0001\right)$.

Firms with low levels of investments in Market Development activities that allow them to deliver variation in the market were able to achieve significant levels Sales Growth in cases where they invested in Capability Development. These enhanced capabilities did not lead to improved Market Development, but they may have led to more efficient and better targeted internal processes as a basis of improved sales growth. Thus, such firms may not have achieved regular variation in the market, but they potentially built a basis for variation relative to competitors in respect of internal efficiencies.

However, where firms are engaging in significant Market Development activities already, those who simultaneously invest in Capability Development actually saw a tailing off of their level of Sales Growth. This suggests that optimizing investments in capability and market development activities require great care. As intimated previously, we suspect that there are lag effects evident in both forms of investment, and more so in investments related to capability development.

One interesting result in testing for Hypothesis 2 was that the deployment of dynamic capabilities did not have a direct effect upon selection as measured by Sales Growth and instead the relationship was mediated by market development - at least in cases where Market Development was relatively low. While the results were obviously far more complex than anticipated, the lack of a direct relationship between capabilities and a performance measure (sales growth) has implications as to the way we commonly define dynamic capabilities. Dynamic capabilities are required to 'address rapidly changing environments' (Teece, Pisano, \& Shuen, 1997: 516) or 'to match and even create market change' (Eisenhardt \& Martin, 2000: 1107). Other definitions align with this notion of adaptation and reconfiguring the firm's resources base, but do not address the variation required in respect of the competition that occurs via the market. For example, Helfat et al. (2007: 4) suggest 'a dynamic capability is the capacity of an organization to purposefully create, extend, or modify its resource base'. Our results reinforce the notion that there is a potentially important role in respect of variation in market activities to enable the link between dynamic capabilities and superior selection outcomes.

\section{LIMITATIONS AND FUTURE EXTENSIONS}

A clear limitation of the study is the degree to which a true Darwinian model involving variation, selection and retention could be assessed. First, the selection mechanism was assessed via a proxy of firm performance. As a proxy, and given the limitation of the data to assess survival, it was probably appropriate. However, one clear objective of this paper was to delineate the DCV from the RBV, including the fact that the DCV via an evolutionary model does not seek to explain competitive advantage (which is often measured by firm performance). Thus, the attempt to clearly position the $\mathrm{DCV}$ as being independent to the RBV is somewhat compromised by using the firm performance construct in much the same way as an RBV study would use it to demonstrate competitive advantage. 
In addition, the constructs of selection and retention adequately were unable to be assessed, though the cumulative aspect of the routines in the Capability Development construct using panel data does provide some evidence of retention beginning the cycle again.

Using Australian service industry data leads to questions regarding the generalizability of the research. However, firms such as these tend to exist in advanced economies around the world as the data covers a variety of industry sectors but consists entirely of SMEs. In addition, through using secondary data from the ABS, we were significantly constrained by the questions asked by the ABS and the time frame over which the data was collected. While the quality of the data was good given the legislative powers provided to the ABS, a longer time frame (as this was a one-off survey by the ABS) may provide more items of relevance in future research studies.

\section{CONCLUDING REMARKS}

Given Peteraf, Stefano, and Verona (2013) noted two 'clubs' in the dynamic capabilities arena centring around Teece, Pisano, and Shuen (1997) or Eisenhardt and Martin (2000) - based on slightly different assumptions, it is appropriate to investigate some of the underlying principles from an empirical standpoint. The Teece approach clearly builds on an evolutionary perspective and this has clear implications for how dynamic capabilities may relate to the RBV - which in this case suggests that the two theories are complementary, but independent. In conceptualizing and testing how variation through market development affects sales growth, and subsequently, how dynamic capabilities impact market development and sales growth mediated by market development, we attempted to gain some initial insight into the potential of using Darwinian concepts in an empirical investigation of dynamic capabilities. The results were not highly conclusive and a more detailed and much longer time series data set would need to be used to do gain a deeper insight. Nevertheless, the Darwinian principles still hold considerable theoretical promise - even if they may be difficult to translate into an empirical setting.

Perhaps surprisingly, one clear outcome of the paper was the capability development and market development has a complex relationship that probably speaks far more to the ambidexterity literature and the challenges of optimizing search strategies with exploitation strategies in the context of the need for continual adaptation and variation within product markets. While an interaction effect between capability development and market development was not unexpected, the way that this interaction effect varied across high and low levels of investments in these two constructs requires further investigation and theorizing.

In conclusion, the paper highlights that the DCV may be conceptualized as an evolutionary process as per the variation, selection and retention mechanisms. Firms can create, build, integrate and deploy resources and capabilities in a path-dependent manner to either meet the needs of a changing environment, or even to take part in the co-evolution of the market. However, the DCV does not directly inform why some firms achieve competitive advantage (other than to infer competitive advantage from the selection mechanism). Our results highlight the importance of variation on a likely antecedent of selection and highlight some issues in further applying a Darwinian style approach to the DCV. In this respect, further empirical research is required to position the DCV as a complementary and dynamic - but independent - theory to the potentially static RBV with a different set of assumptions, a different dependent variable and a different strategic focus.

\section{ACKNOWLEDGEMENTS}

This article was produced with data from the Australian Bureau of Statistics' (ABS) Confidentialised Unit Record File drawn from the Business Longitudinal Survey - 1994-1998. The authors gratefully acknowledge support provided by the ABS without which this work would not have been possible. 


\section{REFERENCES}

Agarwal, R., \& Bayus, B. L. (2002). The market evolution and sales takeoff of product innovations. Management Science, 48, 1024-1041.

Agarwal, R., \& Selen, H. (2013). The incremental and cumulative effects of dynamic capability building on service innovation in collaborative service organizations. Journal of Management \& Organization, 19, 521-543.

Aldrich, H. E. (1979). Organizations and environments. Englewood Cliffs, NJ: Prentice-Hall.

Aldrich, H. E., Hodgson, G. M., Hull, D. L., Knudsen, T., Mokyr, J., \& Vanberg, V. J. (2008). In defence of generalized Darwinism. Journal of Evolutionary Economics, 18, 577-596.

Aldrich, H. E., \& Ruef, M. (2006). Organizations evolving (2nd ed.). London: Sage.

Ambrosini, V., \& Bowman, C. (2009). What are dynamic capabilities and are they a useful construct in strategic management? International Journal of Management Reviews, 11, 29-49.

Arend, R. J., \& Bromiley, P. (2009). Assessing the dynamic capabilities view: Spare change everyone? Strategic Organization, 7, 75-90.

Barnett, W. P., \& Burgelman, R. A. (1996). Evolutionary perspectives on strategy. Strategic Management Journal, 17 (Special Issue), 5-19.

Barney, J. B. (1986). Strategic factor markets: Expectations, luck, and business strategy. Management Science, 32(10), $1231-1241$.

Barney, J. B. (1991). Firm resources and sustained competitive advantage. Journal of Management, 17(Special Issue), 99-120.

Barney, J. B. (2001). Resource-based theories of competitive advantage: A ten-year retrospective on the resource-based view. Journal of Management, 27(Special Issue), 643-650.

Barney, J. B., \& Clark, D. N. (2007). Resource-based theory: Creating and sustaining competitive advantage. New York, NY: Oxford University Press.

Campbell, D. T. (1969). Variation and selective retention on socio-cultural evolution. General Systems, 14, 69-85.

Cohen, M. D., Burkhart, R., Dosi, G., Egidi, M., Marengo, L., Warglien, M., \& Winter, S. (1996). Routines and other recurring action patterns of organizations: Contemporary research issues. Industrial and Corporate Change, 5 , 653-698.

Cohen, W. M., \& Levinthal, D. A. (1990). Absorptive capacity: A new perspective on learning and innovation. Administrative Science Quarterly, 35, 128-152.

Cyert, R. M., \& March, J. G. (1963). A behavioral theory of the firm. Englewood Cliffs, NJ: Prentice Hall.

Durand, R. (2006). Organizational evolution and strategic management. London: Sage.

Eisenhardt, K. M., \& Martin, J. A. (2000). Dynamic capabilities: What are they? Strategic Management Journal, 21, 1105-1121.

Hannan, M. T., \& Freeman, J. (1984). Structural inertia and organizational change. American Sociological Review, 49(2), 149-164.

Helfat, C. E. (2000). Guest editor's introduction to the special issue: The evolution of firm capabilities. Strategic Management Journal, 21(10/11), 955-959.

Helfat, C. E., Finkelstein, S., Michael, P., Peteraf, M. A., Teece, D. J., \& Winter, S. G. (2007). Dynamic capabilities: Understanding strategic change in organizations. Malden, MA: Blackwell Publishing.

Helfat, C. E., \& Peteraf, M. (2003). The dynamic resource-based view: Capability lifecycles. Strategic Management Journal, 24(10), 997-1010.

Hodgson, G. M. (2004). Darwinism, causality and the social sciences. Journal of Economic Methodology, 11, 175-194.

Hodgson, G. M. (2009). Agency, institutions and Darwinism in evolutionary economic geography. Economic Geography, 85, 167-173.

Makadok, R. (2001). Toward a synthesis of the resource-based and dynamic-capability views of rent creation. Strategic Management Journal, 22, 387-401.

Mathews, J. A. (2006). Strategizing, disequilibrium, and profit. Stanford: Stanford University Press.

Miller, D., Le Breton-Miller, I., \& Scholnick, B. (2008). Stewardship vs. stagnation: An empirical comparison of small family and non-family businesses. Journal of Management Studies, 45, 50-78.

Nelson, R. R., \& Winter, S. G. (1982). An evolutionary theory of economic change. Cambridge, MA: Harvard University Press. 
Newey, L. R., Verreynne, M. L., \& Griffiths, A. (2012). The relationship between dynamic and operating capabilities as a stage-gate process: Insights from radical innovation. Journal of Management \& Organization, 18(1), 123-140.

Odling-Smee, F. J., Laland, K. N., \& Feldman, M. W. (2003). Niche construction: The neglected process in evolution. Princeton, NJ: Princeton University Press.

Pablo, A., Reay, T., Dewald, J. R., \& Casebeer, A. L. (2007). Identifying, enabling and managing dynamic capabilities in the public sector. Journal of Management Studies, 44, 687-708.

Penrose, E. T. (1959). The theory of the growth of the firm. New York, NY: John Wiley \& Sons.

Peteraf, M. A. (1993). The cornerstones of competitive advantage: A resource-based view. Strategic Management Journal, 14, 179-191.

Peteraf, M. A., \& Barney, J. B. (2003). Unraveling the resource-based tangle. Managerial and Decision Economics, 24(4), 309-323.

Peteraf, M. A., Stefano, G. D., \& Verona, G. (2013). The elephant in the room of dynamic capabilities: Bringing two diverging conversations together. Strategic Management Journal, 34, 1389-1410.

Pitelis, C. N., \& Teece, D. J. (2009). The (new) nature and essence of the firm. European Management Review, 6, $5-15$.

Porter, M. E. (1991). Towards a dynamic theory of strategy. Strategic Management Journal, 12(Special Issue), 95-117.

Priem, R. L., \& Butler, J .E. (2001). Is the resource-based 'view' a useful perspective for strategic management research? Academy of Management Review, 26(1), 22-40.

Schreyögg, G., \& Kliesch-Eberl, M. (2007). How dynamic can organizational capabilities be? Towards a dual process model of capability dynamization. Strategic Management Journal, 28(9), 913-933.

Schumpeter, J. A. (1982). Business cycles: A theoretical historical, and statistical analysis of the capitalist process (13th ed.). Philadelphia: Porcupine Press, (First edition in 1939, New York, NY: McGraw-Hill).

Sober, E. (1984). The nature of selection: Evolutionary theory in philosophical focus. Cambridge, MA: MIT Press.

Srivastava, R. K., Fahey, L., \& Christensen, H. K. (2001). The resource-based view and marketing: The role of market-based assets in gaining competitive advantage. Journal of Management, 27, 777-802.

Stoelhorst, J. W. (2005). The naturalistic perspective on universal Darwinism: An application to the evolutionary theory of the firm. In J. Finch \& M. Orillard (Eds.), Complexity and the economy: Implications for economic policy (pp. 127-147). Aldershot: Edward Elgar.

Stoelhorst, J. W. (2008). Why is management not an evolutionary science? Evolutionary theory in strategy and organization. Journal of Management Studies, 45(5), 1008-1023.

Teece, D. J. (2007). Explicating dynamic capabilities: The nature and microfoundations of (sustainable) enterprise performance. Strategic Management Journal, 28, 1319-1350.

Teece, D. J., \& Pisano, G. (1994). The dynamic capabilities of firms: An introduction. Industrial and Corporate Change, 3(3), 537-556.

Teece, D., Pisano, G., \& Shuen, A. (1997). Dynamic capabilities and strategic management. Strategic Management Journal, 18, 509-533.

Van Den Bosch, F. A. J., Volberda, H. W., \& De Boer, M. (1999). Co-evolution of firm absorptive capacity and knowledge environment: Organizational forms and combinative capabilities. Organization Science, 10, 551-568.

Williamson, O. E. (1999). Strategy research: Governance and competence perspectives. Strategic Management Journal, 20(12), 1087-1108.

Winter, S. G. (2003). Understanding dynamic capabilities. Strategic Management Journal, 24(10), 991-995.

Zahra, S. A., Sapienza, H. J., \& Davidsson, P. (2006). Entrepreneurship and dynamic capabilities: A review, model and research agenda. Journal of Management Studies, 43(4), 917-955.

Zhao, X., Lynch, J., \& Chen, Q. (2010). Reconsidering Baron and Kenny: Myths and truths about mediation analysis. Journal of Consumer Research, 37(2), 196-206.

Zollo, M., \& Winter, S. G. (2002). Deliberate learning and the evolution of dynamic capabilities. Organization Science, 13, 339-351.

Zott, C. (2003). Dynamic capabilities and the emergence of intraindustry differential firm performance: Insights from a simulation study. Strategic Management Journal, 24, 97-125. 